\title{
Influence of pressure and radio frequency power on deposition rate and structural properties of hydrogenated amorphous silicon thin films prepared by plasma deposition
}

\author{
J.L. Andújar, E. Bertran, A. Canillas, C. Roch, and J. L. Morenza \\ Universitat de Barcelona, Departament de Fisica Aplicada i Electrònica, Av. Diagonal 647. \\ 08028-Barcelona, Spain
}

(Received 20 September 1990; accepted 9 March 1991)

\begin{abstract}
The influence of radio frequency ( $\mathrm{rf}$ ) power and pressure on deposition rate and structural properties of hydrogenated amorphous silicon $(a-\mathrm{Si}: \mathrm{H})$ thin films, prepared by rf glow discharge decomposition of silane, have been studied by phase modulated ellipsometry and Fourier transform infrared spectroscopy. It has been found two pressure regions separated by a threshold value around $20 \mathrm{~Pa}$ where the deposition rate increases suddenly. This behavior is more marked as If power rises and reflects the transition between two rf discharges regimes ( $\alpha$ and $\gamma$ ). The best quality films have been obtained at low pressure and at low rf power but with deposition rates below $0.2 \mathrm{~nm} / \mathrm{s}$. In the high pressure region, the enhancement of deposition rate as $\mathrm{rf}$ power increases first gives rise to a reduction of film density and an increase of content of hydrogen bonded in polyhydride form because of plasma polymerization reactions. Further rise of $\mathrm{r} f$ power leads to a decrease of polyhydride bonding and the material density remains unchanged, thus allowing the growth of $a-\mathrm{Si}: \mathrm{H}$ films at deposition rates above $1 \mathrm{~nm} / \mathrm{s}$ without any important detriment of material quality. This overcoming of deposition rate limitation has been ascribed to the beneficial effects of ion bombardment on the $a$-Si:H growing surface by enhancing the surface mobility of adsorbed reactive species and by eliminating hydrogen bonded in polyhydride configurations.
\end{abstract}

\section{INTRODUCTION}

Nowadays hydrogenated amorphous silicon $(a-\mathrm{Si}: \mathrm{H})$ has become a common material for fabricating photovoltaic and electronic devices, such as solar cells and thin film transistors.' Plasma enhanced chemical vapor deposition (PECVD) by If glow discharge decomposition of $\mathrm{SiH}_{4}$ at $13.56 \mathrm{MHz}$, is the most widely used method for preparing $a$ $\mathrm{Si}: \mathrm{H}$ thin films, but the deposition rate of high quality films is rather limited, typically in the range $0.1-0.5 \mathrm{~nm} / \mathrm{s}$. One solution for reducing the cost of $a-\mathrm{Si}: \mathrm{H}$ based devices is to achieve higher deposition rates without reducing film quality. To attain this goal there are two different approaches. One is to employ other depositions techniques such as photo $\mathrm{CVD}^{2}{ }^{2}$ activated reactive evaporation ${ }^{3}$ and electron cyclotron resonance CVD. ${ }^{4}$ However, these methods are technologically premature or have several disadvantages for mass production. The other is to retain the conventional PECVD technique and introduce some modifications, such as the use of higher silanes as feed gas, ${ }^{5}$ the application of magnetic fields, ${ }^{6}$ and the shift of excitation frequency to the very high frequency range. ${ }^{7}$ These modifications have not been fully explored yet, and so far the photovoltaic conversion efficiencies of $a$-Si:H solar cells fabricated at high deposition rates are lower than those obtained by using conventional low deposition rate methods.

Actually, the easiest way to enhance the deposition rate in a PECVD system is by increasing both the silane gas pressure and the rf power. On the one hand, it is generally agreed that increasing the pressure gives rise to gas phase polymer- ization reactions, ${ }^{8}$ that result in powder formation and deterioration of film properties as the deposition rate increases. On the other hand, the rf power influence is not so clear and, although it is known that high values of $\mathrm{rf}$ power increase the probability of plasma polymerization reactions, ${ }^{9}$ there are studies showing that increasing the rf power first leads to a deterioration and then to an improvement of $a-\mathrm{Si}: \mathrm{H}$ film properties as the deposition rate increases. ${ }^{10,11}$

In a previous work ${ }^{12}$ we have presented preliminary results about the effects induced by increasing the pressure at constant rf power on the deposition rate of $a-\mathrm{Si}: \mathrm{H}$ films. At a certain pressure one observed a sudden increase in the deposition rate, as well as a fall of both the rf voltage amplitude and the magnitude of the dc self-bias voltage of the $\mathrm{rf}$ electrode. These observations reflect a transition between two regimes ( $\alpha$ and $\gamma$ ) of the silane rf discharge. ${ }^{13}$ In the low pressure $\alpha$ regime the power is dissipated in the bulk plasma region by electrons gaining their energy at the oscillating plasma sheath edges, whereas in the $\gamma$ regime the dominant mechanism is the ionization and dissociation in the sheaths by the acceleration of secondary electrons emitted at the electrodes. A significant deterioration of optoelectronic and structural properties of $a$-Si:H films deposited in the high pressure $\gamma$ regime was reported in Ref. 13 as compared with those obtained in the low deposition rate $\alpha$ regime.

In order to gain more insight into the effects induced by pressure and $\mathrm{rf}$ power, this paper reports a study of the influence of both parameters, in a wide range, on the deposition rate and structural properties of $a$-Si:H thin films prepared in a PECVD reactor. 


\section{EXPERIMENT}

The deposition system consists of a capacitively coupled if plasma reactor provided with a computer controlled gassupply and pumping system ${ }^{14}$ and equipped with a phase modulated ellipsometer. ${ }^{15}$ Inside the reactor there is a plasma confinement chamber, which has a parallepipedical geometry and is constituted by two parallel electrodes vertically placed $\left(400 \mathrm{~cm}^{2}\right.$ in area and separated by $\left.4 \mathrm{~cm}\right)$ and by four lateral confinement walls. The rf electrode is connected to a $13.56 \mathrm{MHz}$ generator via an automatic matching network, whereas the substrate electrode as well as the lateral confinement walls are grounded. Thus, the effective area ratio between the if electrode and the grounded electrode is about 0.5 . The feed gas flows downstream along the electrode gap through two slits located in the upper and the lower lateral confinement wall, respectively.

The $a-\mathrm{Si}: \mathrm{H}$ thin films were deposited on crystalline silicon wafers and Corning 7059 glass substrates heated at $300^{\circ} \mathrm{C}$. The flow rate of pure $\mathrm{SiH}_{4}$ gas was monitored and kept constant at $30 \mathrm{sccm}$ by means of a mass flow controller. The deposition pressure was varied in the range 3-50 $\mathrm{Pa}$ by regulating the pumping conductance and was measured by a capacitance manometer. The if power supplied to the discharge ranged from 5 up to $80 \mathrm{~W}$.

The deposition rate of the films was determined by in situ real time ellipsometry at a fixed wavelength ${ }^{16}$ or by optical transmittance measurements in the near infrared (NIR) range. ${ }^{17}$

was measured in the UV-visible range by ex situ spectroscopic ellipsometry.

The infrared absorption properties of the films were studied by means of a Fourier transform infrared spectrometer (Nicolet 5ZDX FT-IR) in the $4000-400 \mathrm{~cm}^{-1}$ wave number range. From the wagging absorption mode at $630 \mathrm{~cm}^{-1}$ the content of bonded hydrogen in the films was deter- mined. ${ }^{18}$ In addition, we calculated the so-called parameter of microstructure R (Refs. 19 and 20) defined as,

$$
R=[2090] /([2090]+[2000]) \text {, }
$$

where [2000] and [2090] represent the integrated band intensities of the IR stretching modes centered at 2000 and $2090 \mathrm{~cm}^{-1}$, respectively. In $a$-Si:H films, the $2000 \mathrm{~cm}^{-1}$ mode corresponds to monohydride $\mathrm{SiH}$ bonding, ${ }^{21}$ whereas the $2090 \mathrm{~cm}^{-1}$ mode is associated with polyhydride $\left(\mathrm{SiH}_{2}\right)_{n}$ groups $^{21}$ and monohydride bonds on internal surfaces. ${ }^{22}$ Therefore this parameter is indicative of the hydrogen bonded in some sort of microstructure.

\section{RESULTS}

Figure 1 shows the deposition rate of the $a$-Si:H thin films as a function of pressure at different values of $\mathrm{rf}$ power. As for moderate if powers $(5,10$, and $20 \mathrm{~W})$ there is a threshold value around $20 \mathrm{~Pa}$ where the deposition rate rises suddenly until reaching a maximum and then decreases. This enhancement of deposition rate becomes stronger as the if power rises, and it is accompanied by a decrease of both the rf voltage amplitude and the magnitude of the dc selfbias voltage on the rf electrode, as we have reported previously. ${ }^{12}$ At higher if powers ( 50 and $80 \mathrm{~W}$ ), the deposition rate rises with increasing pressure over the explored range reaching values above $1 \mathrm{~nm} / \mathrm{s}$. In this $\mathrm{rf}$ power range it was not possible to obtain useful samples at low pressure, because the films blistered after taking them out the chamber. In Fig. 2, we show the rf power dependence of the deposition rate at constant pressure. At $20 \mathrm{~Pa}$ this dependence is practically linear, whereas at higher pressures the deposition rate shows first a sharp rise for rf powers up to $30 \mathrm{~W}$ and after that increases more slightly.

The $\epsilon_{2}$ spectra of the $a$-Si:H films show a maximum around $3.5 \mathrm{eV}$ of photon energy. This maximum value of $\epsilon_{2}$,

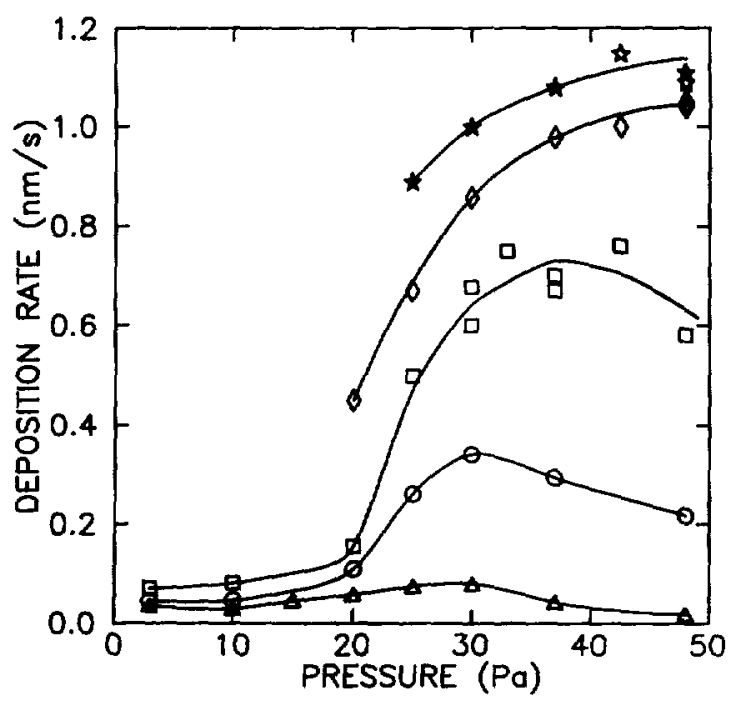

FIG. 1. Deposition rate of $a-$ Si:H films vs pressure at different if power levels: $5 \mathrm{~W}$ (triangles), $10 \mathrm{~W}$ (circles), $20 \mathrm{~W}$ (squares), $50 \mathrm{~W}$ (diamonds), and $80 \mathrm{~W}$ (stars).

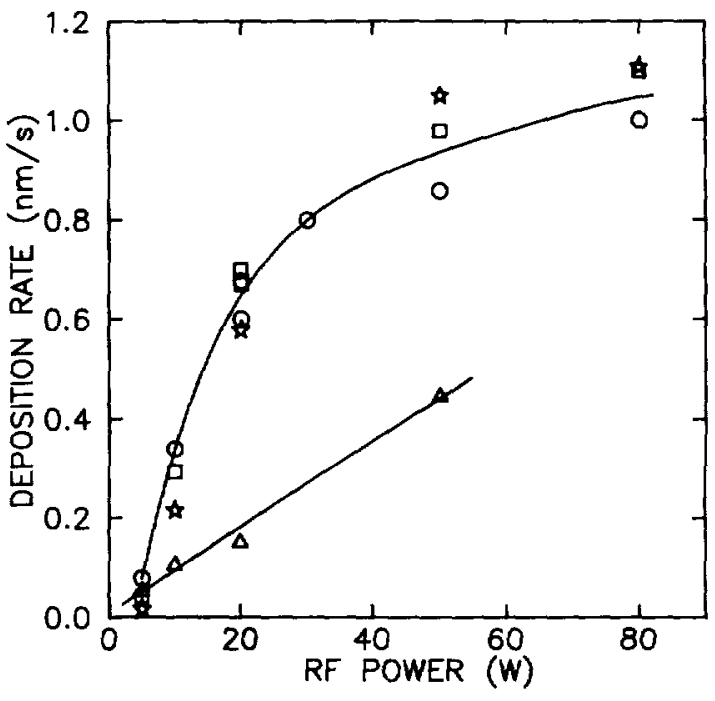

Fig. 2. Dependence of film deposition rate on rf power at different deposition pressures: $20 \mathrm{~Pa}$ (triangles), $30 \mathrm{~Pa}$ (circles), $37 \mathrm{~Pa}$ (squares), and 48 Pa (stars). 


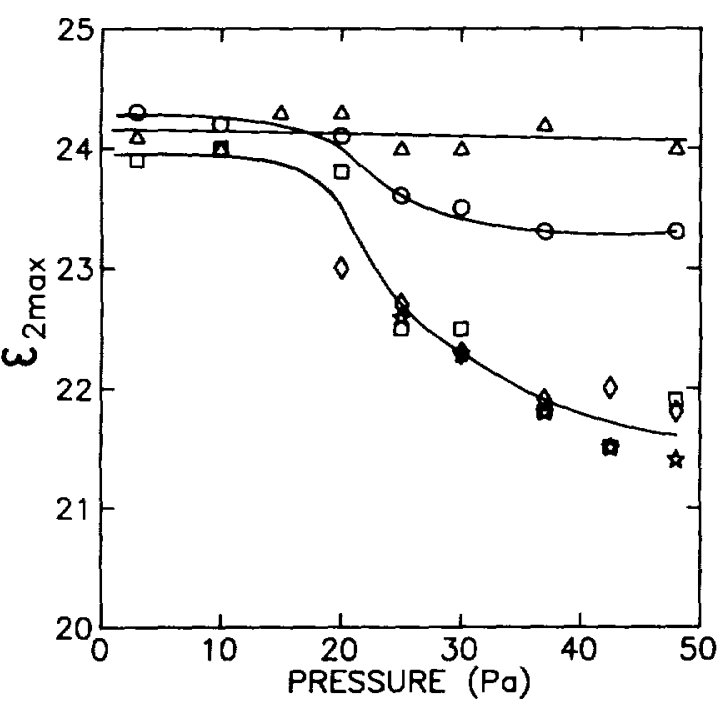

Fig. 3. Pressure dependence of the maximum value of $\epsilon_{2}$, measured at room temperature by ex situ ellipsometry, for different of powers: $5 \mathrm{~W}$ (triangles), $10 \mathrm{~W}$ (circles), $20 \mathrm{~W}$ (squares), $50 \mathrm{~W}$ (diamonds), and $80 \mathrm{~W}$ (stars).

$\epsilon_{2 \max }$, is related to the film bulk density and surface roughness. ${ }^{23}$ The variations of $\epsilon_{2 \max }$ with deposition pressure and rf power are plotted in Figs. 3 and 4. At low rf power ( $5 \mathrm{~W}$ ) one does not observe any significant variation of $\epsilon_{2 \max }$ with increasing pressure. At higher rf power the same behavior is observed at low pressures, but, as soon as the pressure rises above $20 \mathrm{~Pa}$, the increase of the deposition rate is accompanied by a decrease in $\epsilon_{2 \max }$. This fall is sharper as the if power is increased until $20 \mathrm{~W}$ (Fig. 4), where $\epsilon_{2 \max }$ becomes practically independent of the if power value.

Figure 5 shows the rf power influence on the hydrogen content in $a$-Si:H films, $C_{\mathrm{H}}$, for different deposition pres-

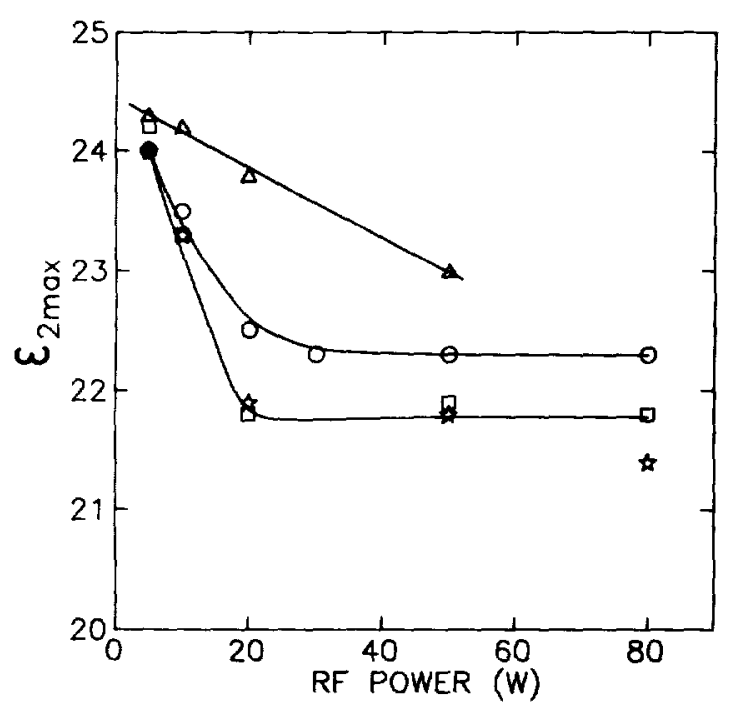

FIG. 4. Variation of $\epsilon_{2 \max }$ as a function of $\mathrm{ff}$ power at different deposition pressures: $20 \mathrm{~Pa}$ (triangles), $30 \mathrm{~Pa}$ (circles), $37 \mathrm{~Pa}$ (squares), and $48 \mathrm{~Pa}$ (stars).

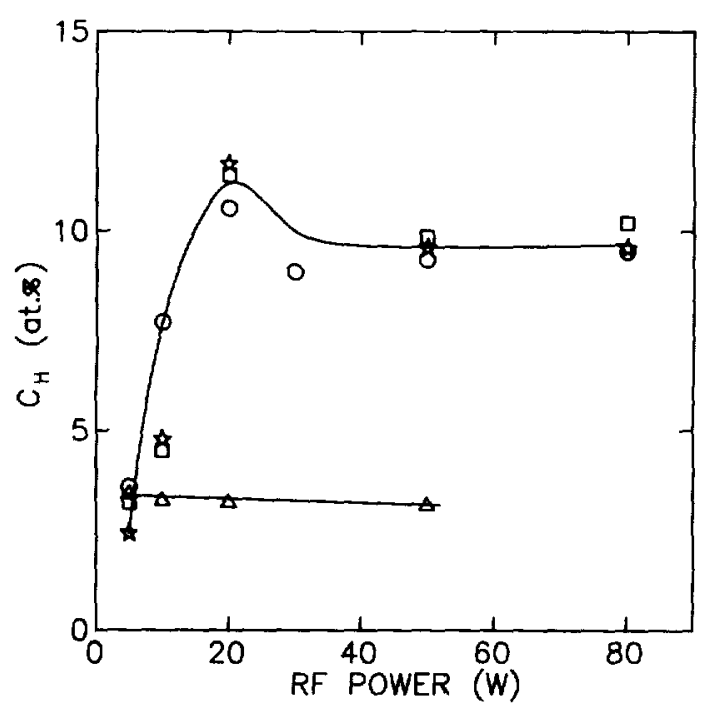

Fig. 5. Dependence of hydrogen content, $C_{\mathrm{H}}$, on if power for different deposition pressures: $20 \mathrm{~Pa}$ (triangles), $30 \mathrm{~Pa}$ (circles), $37 \mathrm{~Pa}$ (squares), and $48 \mathrm{~Pa}$ (stars)

sures. At low pressure ( $20 \mathrm{~Pa}$ ), $C_{\mathrm{H}}$ shows a constant value around 3 at.\%. At higher pressures, $C_{H}$ first rises rapidly with the increase of $\mathrm{rf}$ power, reaches a maximum at $20 \mathrm{~W}$ and then decreases slightly showing constant values close to 9 at.\%.

The variation of the parameter of microstructure $R$ as a function of $\mathrm{rf}$ power is shown in Fig. 6. Two different behavior patterns are observed depending on deposition pressure. At $20 \mathrm{~Pa}$ the increase of $\mathrm{of}$ power from $5 \mathrm{~W}$ up to $10 \mathrm{~W}$ leads to an initial increment of $R$ and afterwards the values of $R$ remain around 0.1 . In contrast, at higher pressures the $\mathrm{rf}$ power dependences of $R$ show a clear maximum at $20 \mathrm{~W}$.

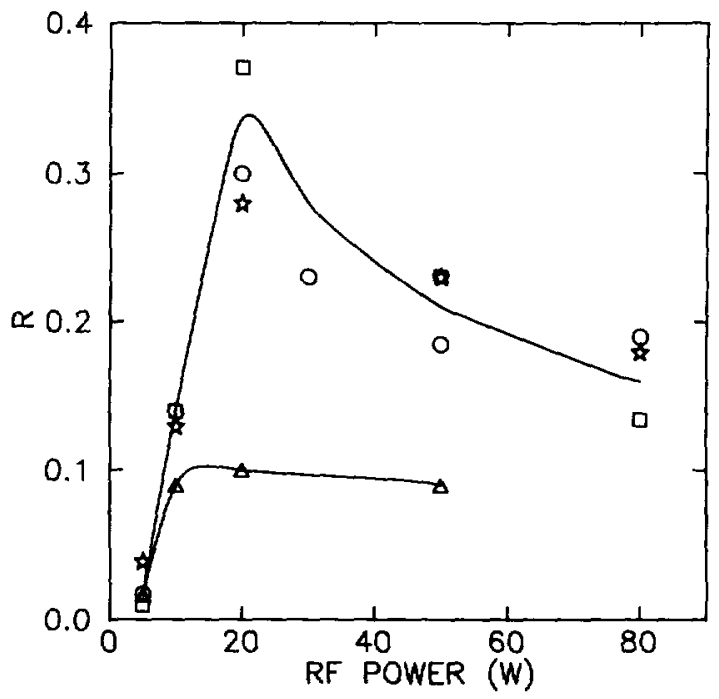

FIG. 6. Dependence of the microstructure parameter, $R$, on if power for different deposition pressures: $20 \mathrm{~Pa}$ (triangles), $30 \mathrm{~Pa}$ (circles), $37 \mathrm{~Pa}$ (squares), and $48 \mathrm{~Pa}$ (stars).

J. Vac. Sci. Technol. A, Vol. 9, No. 4, Jul/Aug 1991 


\section{DISCUSSION}

The pressure dependence of deposition rate at constant if power can be understood in terms of the $\alpha-\gamma$ discharge transition. ${ }^{13}$ The sudden increase of the deposition rate as soon as the rf discharge enters the $\gamma$ regime is mainly due to the proximity of the substrate to the silane dissociation zone, whereas in the $\alpha$ regime the dissociation takes place throughout the bulk plasma region. In the $\gamma$ regime, for low and intermediate if power levels, the subsequent decrease of the deposition rate after reaching a maximum is caused, in part, by a decrease of the electronic temperature due to the increase of the pressure. Another cause arises from the limitation of deposition rate by gas phase polymerization, which is revealed by powder formation at conditions of high pressure and $\mathrm{rf}$ powers above $10 \mathrm{~W}$. Nevertheless, the yellow powder is observed always outside the plasma confinement chamber and is neither stuck to the films nor to the confinement walls. At high $\mathrm{rf}$ powers ( 50 and $80 \mathrm{~W}$ ) this decrease in deposition rate is not shown because of the induced enhancement of plasma electronic density that favors the ion and radical generation in the plasma. However, the rf power dependence of deposition rate (Fig. 2) tends to saturate at high rf powers and high pressures, as a result of the gas phase polymerization and the consumption of species contributing to film growth.

The consequences of increasing the deposition rate on $a$ Si:H film quality is shown in Fig. 7, where the $\epsilon_{2 \max }$ values corresponding to films deposited at different $\mathrm{rf}$ powers and pressures are plotted against the deposition rate. This representation indicates that the enhancement of deposition rate by increasing pressure or $\mathrm{rf}$ power is at the expense of a reduction of film quality refiected in the value of $\epsilon_{2 \max }$. Nevertheless, this decrease is not very strong since, for example, the $\epsilon_{2 \max }$ values of films grown at $1 \mathrm{~nm} / \mathrm{s}$ are only $10 \%$ lower

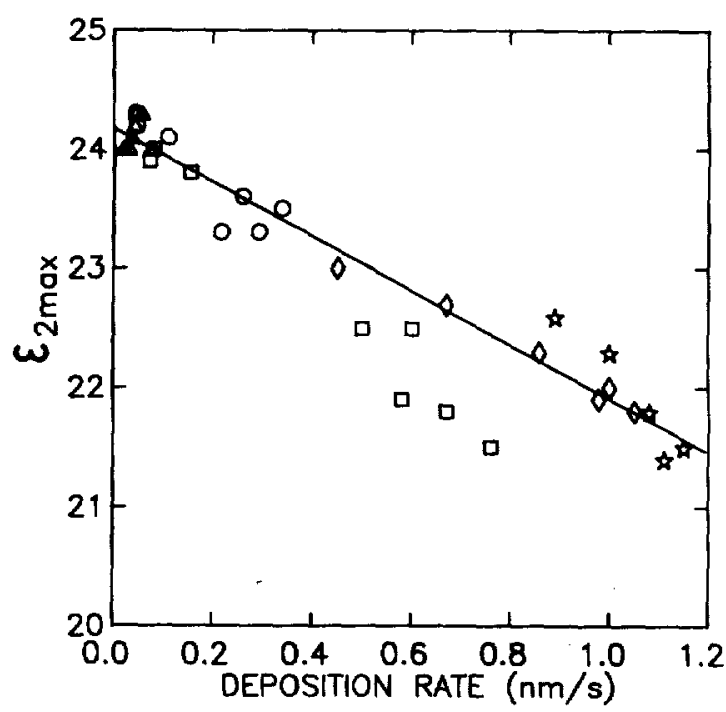

Fig. 7. Deposition rate correlation of $\epsilon_{2 \max }$ corresponding to $a-\mathrm{Si}: \mathbf{H}$ films deposited at $300^{\circ} \mathrm{C}$ in the pressure range $3-50 \mathrm{~Pa}$ at different rf power levels: $5 \mathrm{~W}$ (triangles), $10 \mathrm{~W}$ (circles), $20 \mathrm{~W}$ (squares), $50 \mathrm{~W}$ (diamonds), and 80 W (stars) than those corresponding to films grown below $0.1 \mathrm{~nm} / \mathrm{s}$. Another feature shown in Fig. 7 is that the films deposited at $20 \mathrm{~W}$ in the high pressure region which have higher values of $R$ (Fig. 6), also exhibit $\epsilon_{2 \max }$ values below the overall dependence represented by the solid line in the figure,

$\epsilon_{2 \max }=-2.27 \cdot \mathrm{DR}+24.2(\mathrm{DR}$ in $\mathrm{nm} / \mathrm{s})$.

As a matter of fact, a decrease of $\epsilon_{2 \max }$ measured by ellipsometry qualitatively means a decrease of material density and/or an increase of film surface roughness. In order to elucidate both contributions to the decrease of $\epsilon_{2 \max }$ with deposition rate, the complex dielectric function spectra of some films have been analyzed by applying the Bruggeman effective medium approximation ${ }^{24}$ and a linear regression analysis. ${ }^{23}$ From that, the bulk void fraction and the surface roughness have been estimated assuming a two layers model. ${ }^{25}$ The reference dielectric function for dense $a-\mathrm{Si}: \mathrm{H}$ used in the calculations has an $\epsilon_{2 \max }$ value of 28.8 at $3.74 \mathrm{eV}$. The surface roughness layer was modeled using a $0.395 / 0.605$ volume fraction mixture of void and $a$-Si: $\mathrm{H}$ that corresponds to a hemispherical roughness topology. Table I summarizes the results of these analyses which show a gradual increase in the bulk void fraction as the deposition rate rises, whereas the surface roughness does not change significantly. Therefore, we mainly attribute the decrease of $\epsilon_{2 \max }$ with increasing deposition rate to a reduction of film density.

The $\mathrm{rf}$ power dependences of deposition rate, $\epsilon_{2 \max }$ and $R$ (Figs. 2, 4, and 6) indicate that a certain improvement of the compromise between film quality and deposition rate is attained by increasing rf power. This observation is in accordance with the results published in Refs. 10 and 11 , where it was reported that the initial deterioration of opto-electronic properties of $a-\mathrm{Si}: \mathrm{H}$, as the rf power is increased, is recovered by going to higher if power levels. Potts et al. ${ }^{10}$ ascribed this improvement to ion bombardment of the growing surface, whereas Nishikawa et al." proposed a model based on a change in the precursor radical of film deposition with the increase of $\mathrm{f} f$ power.

Since the ion bombardment in wall confined $r f$ discharges is more enhanced than in unconfined ones, ${ }^{26}$ we will try to analyze our experimental data in the following in terms of the effects induced by ion bombardment. In relation to ion bombardment, the influences of the if power and the pressure are opposed. ${ }^{27}$ The increase of plasma potential by ris-

TABLE I. Parameters used to fit the $\tilde{\boldsymbol{\epsilon}}$ spectra of $a$-Si:H films deposited at different deposition rates assuming a two layers model. The estimated uncertainties for the bulk void fraction $\left(f_{c}\right)$ and the surface roughness $\left(r_{s}\right)$ are $\pm 0.5 \%$ and $\pm 0.5 \mathrm{~nm}$, respectively. The $r$, values include the influence of the native oxide of the films.

\begin{tabular}{ccc}
\hline $\begin{array}{c}\mathrm{DR} \\
(\mathrm{nm} / \mathrm{s})\end{array}$ & $\begin{array}{c}f_{r} \\
(\%)\end{array}$ & $\begin{array}{c}r_{\mathrm{r}} \\
(\mathrm{nm})\end{array}$ \\
\hline 0.05 & 1.2 & 3.3 \\
0.4 & 2.1 & 3.6 \\
0.6 & 4.9 & 2.8 \\
1.1 & 6.9 & 3.9 \\
\hline
\end{tabular}


ing If power at constant pressure leads to an enhancement of both the energy and the flux of ions to the substrate, whereas the increase of pressure at constant $\mathrm{rf}$ power gives rise to a decrease of the ion flux and energy caused by the increase of collisions within the plasma. It must be pointed out that ion bombardment on a growing $a$-Si:H film may have either detrimental or beneficial consequences on the film quality. On the one hand, the ion bombardment can damage $a$-Si:H creating defects in the material underneath the growing surface, introducing strains in the network and sputtering off radicals. ${ }^{28}$ As a matter of fact, the damaging effect of stress is revealed by the peeling of films deposited at low pressure and high $\mathrm{rf}$ power. On the other hand, the beneficial effects of ion bombardment include the enhancement of surface mobility of adsorbed reactive species by lateral momentum transfer of ions, and the removal from the film surface of loosely adherent species. The former beneficial effect, similar to that produced by increasing substrate temperature, helps to grow a denser material, ${ }^{29}$ whereas the second leads to a decrease of the content of weakly bonded hydrogen, generally in polyhydride form. ${ }^{30}$

The densification of material caused by ion bombardment is reflected in the dependences of $\epsilon_{2 \max }$ shown in Figs. 3 and 4. In the high pressure region, the rise of deposition rate by increasing the rf power from 20 to $80 \mathrm{~W}$ (Figs. 1 and 2) is not accompanied by a reduction of $\epsilon_{2 \max }$ (Fig. 4). At constant rf power (Fig. 3), the decrease of $\epsilon_{2 \max }$ as the pressure is increased is due to the moderation of ion bombardment. Another reason for the densification of the material comes from the fact that at high rf power and high pressure (high deposition rate) silane gas is to some extent depleted and diluted in hydrogen, as shown by a red shift of the plasma optical emission, which favors the diffusion of adsorbed reactive species on the growth surface ${ }^{31}$ as well as the enhancement of ion bombardment. ${ }^{27}$

The elimination of weakly bonded hydrogen as a result of ion bombardment is consistent with the rf power dependences of the hydrogen content and the parameter of microstructure $R$ shown in Figs. 5 and 6, where it is concluded that the excess of microstructure shown by the films deposited at $20 \mathrm{~W}$ in the high pressure region is due to hydrogen bonded in polyhydride form, which is known to have a negative influence on electronic properties of $a-\mathrm{Si}: \mathrm{H}$ films. ${ }^{21}$

\section{v. CONCLUSIONS}

The existence of two $\mathrm{SiH}_{4} \mathrm{rf}$ discharge regimes ( $\alpha$ and $\gamma$ ) has important consequences on the deposition rate of $a$-Si:H thin films. The transition between the two regimes is characterized by a sudden increase of deposition rate as soon as the deposition pressure overcomes a threshold value (around 20 $\mathrm{Pa}$ in our discharges). In the $\gamma$ regime of high pressure, the increase of deposition rate as rf power rises until $20 \mathrm{~W}$ causes a decrease of material density and an increase of hydrogen linked in polyhydride configuration. Nevertheless, at higher rf power the material density is hardly affected and the hydrogen bonded in polyhydride form decreases. We have ascribed this improvement to the ion bombardment action on the $a-\mathrm{Si}: \mathrm{H}$ growing surface that increases the surface mobil- ity of adsorbed reactive species and eliminates weakly bonded hydrogen.

As a main conclusion, the above results show the possibility of obtaining $a-\mathrm{Si}: \mathrm{H}$ thin films at high deposition rates (above $1 \mathrm{~nm} / \mathrm{s}$ ), by working at high rf powers ( $50-80 \mathrm{~W}$ ) and at moderately high pressures $(30-50 \mathrm{~Pa})$, without any important reduction of film quality as compared with that obtained at low deposition rate (below $0.2 \mathrm{~nm} / \mathrm{s}$ ). Although this conclusion is based on FT-IR and ellipsometric data, electrical conductivity and photoconductivity measurements of the films also show an improvement of the optoelectronic properties after an initial deterioration as the rf power is increased, which will be the object of a further work. Overcoming the limitation of deposition rate is very important from the viewpoint of $\boldsymbol{a}-\mathrm{Si}: \mathrm{H}$ applications.

In order to establish the best compromise between film quality and deposition rate, the knowledge of the $a-\mathrm{Si}: \mathrm{H}$ rf plasma deposition process should be improved by fully exploring all deposition parameters.

\section{ACKNOWLEDGMENTS}

This work has been supported by the CAICYT del Ministerio de Educación y Ciencia of Spain (project 798/84). We thank A. Lloret (École Polytechnique, Palaiseau, France) for valuable discussions, and we acknowledge to Serveis Cientifico-Tècnics of University of Barcelona for the optical transmittance measurements.

'A. Madan and M. P. Shaw, The Physics and Applications of Amorphous Semiconductors (Academic Press, San Diego, 1988).

${ }^{2}$ W. Y. Kim, M. Konagai, and K. Takahashi, Jpn. J. Appl. Phys. 27, L948 (1988).

${ }^{3}$ M. Shindo, S. Sato, I. Myokan, S. Mano, and T. Shibata, Jpn. J. Appl. Phys. 24, 14 (1985).

${ }^{4}$ T. Watanabe, M. Tanaka, K. Azuma, M. Kakatani, T. Sonobe, and T. Shimada, Jpn. J. Appl. Phys. 26, 1215 ( 1987 ).

${ }^{5}$ B. A. Scott, M. H. Brodsky, D. C. Green, P. B. Kirby, R. M. Placenick, and E. E. Simonyi, Appl. Phys. Lett. 37, 725 (1980)

${ }^{\circ} \mathrm{H}$. Watanabe, H. Warashina, and T. Nagashima, Thin Solid Films 129, L65 (1985).

${ }^{7}$ H. Curtins, N. Wyrsch, and A. V. Shah, Electron. Lett. 23, 228 (1987)

${ }^{8}$ M. H. Brodsky, Thin Solid Films 10, L23 (1987).

${ }^{9}$ R. C. Ross and J. Jaklik, J. Appl. Phys. 55, 3785 (1984)

'1'J. E. Potts, E. M. Peterson, and J. A. McMillan, J. Appl. Phys. 52, 6665 (1981).

"S. Nishikawa, H. Kakinuma, T. Watanabe, and K. Nihei, Jpn. J. Appl. Phys. 24, 639 (1985)

12 J. L. Andújar, A. Canillas, E. Bertran, and J. L. Morenza, Proc. 9th Int. Symp. on Plasma Chemistry (ISPC-9), Pugnochiuso-Italy, p. 1323 (1989)

13 J. Perrin, P. Roca i Cabarrocas, B. Allain, and J. M. Friedt, Jpn. J. Appl Phys. 27, 2041 (1988).

14 J. L. Andújar, E. Bertran, A. Canillas, J. Andreu, J. Esteve, and J. L. Morenza, Vacuum 39, 795 (1989).

${ }^{15}$ A. Canillas, E. Bertran, J. L. Andújar, and J. L. Morenza, Vacuum 39, 785 (1989).

${ }^{16}$ B. Drévillon, Thin Solid Films 163, 157 (1988)

${ }^{17}$ J. Aranda, J. L. Morenza, J. Esteve, and J. M. Codina, Thin Solid Films 120, 23 (1984).

${ }^{18}$ H. Shanks, C. J. Fang, L. Ley, M. Cardona, F. J. Demond, and S. Kalbitzer, Phys. Status Solidi B100, 43 (1980)

${ }^{19}$ E. Bhattacharya and A. H. Mahan, Appl. Phys. Lett. 52, 1587 (1988). ${ }^{201}$ I. Sakata, M. Yamanaka, S. Okazaki, and Y. Hayashi, Appl. Phys. A48, 295 (1989). 
${ }^{21}$ J. C. Knights, G. Lucovsky, and R. J. Nemanich, J. Non-Cryst. Solids 32, 393 (1979).

${ }^{22}$ H. Wagner and W. Beyer, Solid State Commun. 48, 585 (1983).

${ }^{23}$ D. E. Aspnes, Thin Solid Films 89, 249 (1982).

${ }^{24}$ D. A. G. Bruggeman, Ann. Phys. (Leipzig) 24, 636 (1934).

${ }^{25}$ D. E. Aspnes, J. B. Theeten, and F. Hottier, Phys. Rev, B 20, 3292 (1979).

${ }^{26}$ T. Hamasaki, M. Ueda, A. Chayahara, M. Hirose, and Y. Osaka, Appl
Phys. Lett. 44, 66 (1984)

${ }^{27}$ P. Roca i Cabarrocas, Mater. Res. Soc. Symp. Proc. 149, 33 (1989).

${ }^{28}$ A. Gallagher and J. Scott, Solar Cells 21, 147 (1987).

${ }^{29}$ B. Drévillon, J. Perrin, J. M. Siefert, J. Huc, A. Lloret, G. de Rosny, and J.

P. M. Schmitt, Appl. Phys. Lett. 42, 801 (1983)

${ }^{30}$ G. Sardin, J. Andreu, J. C. Delgado, and J. L. Morenza, Solar Energy Mat. 17, 227 ( 1988 )

${ }^{31}$ K. Tanaka and A. Matsuda, Mater. Sci. Rep. 2, 139 (1987). 